\title{
Sensory reinforcement and response facilitation
}

\author{
G. LOWE AND D. I. WILLIAMS \\ HULL UNIVERSITY, ENGLAND
}

Following a period in a dark box, four groups of rats received either (1) illumination of a display chamber contingent upon a response (E1 and E2), or (2) no responsecontingent illumination (C1 and C2). For El and C1 the chamber contained a live rat. Two factors were isolated: (a) a light reinforcement effect in EI and E2, and (b) a response facilitation factor resulting in $E 1$ responding more than $E 2$.

Under certain conditions, animals will behave so as to increase the variability of their environment. For example, they will learn a task in order to produce variable visual stimulation (e.g., Butler, 1954; Williams \& Lowe, 1967). This "sensory reinforcement" effect is apparently unrelated to such organic drive states as hunger and thirst, and has been demonstrated in several species under various conditions, although visual stimulation has been the most effective reinforcer. While it is clear that light onset can act as a reinforcer, the conditions under which it does so are far from clear.

If rats will respond in order to receive visual stimulation, then it might be expected that the response rate is dependent on such factors as the intensity and variability of the stimulation. Much of the research on light reinforcement has been concerned with the intensity factor (e.g., Barnes, Kish, \& Wood, 1959), and the findings generally indicate a curvilinear relationship between intensity of stimulation and its reinforcing powers. There has, however, been comparatively little work on the stimulus variability aspect, although this would appear to be the more important factor. Such studies have been concerned mainly with visual exploration, where, for example, it has been shown that rats prefer the arm of a maze affording the greater degree of stimulus variation (Dember, Earl, \& Paradise, 1957). Moreover, using a discrimination task, Butler (1953) showed that monkeys would learn in situations where the only incentive was a very brief period of visual exploration (i.e., monkeys were simply allowed to look through a peep-hole at the external environment). More recently, Barnes \& Baron (1961), using mice, found that complex visual patterns were more reinforcing than simple visual patterns.

However, although the reinforcing effects of stimulus variability have been adequately demonstrated, very few attempts have been made to determine and assess the particular factors contributing to these effects. Following along the lines of Butler's experiments, it was decided to use in this experiment a live animal (a rat) as the reinforcing stimulus, this being in a display chamber in the end wall of the experimental box, and could be illuminated by response-contingent light. It has been demonstrated that a live rat can function as a goal in locomotor exploration situations (Stevenson \& Simmel, 1967), where it appears that preference for a particular animal is more a function of novelty rather than of gregarious behavior. Thus, it was expected that a rat would respond more to illuminate a chamber containing a live rat than to illuminate an empty one.

\section{Method}

The experimental box was sound-insulated and measured $10 \times 10 \times 10 \mathrm{in}$. It had a metal grid floor with walls and lid of Perspex, which were black except for the end wall which was white. In this end wall was a single lever 2 in. wide, extending 1 in. into the box; 1 in. above the lever was a clear Perspex panel 6 in. wide and 3-1/2 in. high, set into the wall. Through this panel a display chamber constructed in white Perspex could be viewed. This was 4 in. deep and was evenly illuminated from above by six festoon bulbs fixed above the white Perspex ceiling of the chamber. When the light was on, a meter reading at a point in the box 3 in. from the end wall and 3 in. above the lever was $1.5 \mathrm{ft}-\mathrm{c}$.

Thirty-six male and female hooded rats, aged between 90 and 100 days, were used. They were raised and maintained under normal laboratory illumination, with free access to food and water. For the duration of the experiment they were kept in individual wire mesh cages, but could see the rat in the adjoining cage. Each rat was placed in the dark experimental box with the display chamber empty and with no response-contingent illumination for $30 \mathrm{~min}$ on each of two consecutive days. They were then divided into four groups of nine rats, matched on the basis of their responding in this two day baseline period. In the experimental sessions which were run on the following three days (30 min each day), two experimental groups (E1 and E2) had the display chamber illuminated for 1 sec contingent upon a lever press. The two control groups (C1 and C2) had no such response-contingent illumination. For Group E1 and Group C1 the display chamber contained a live rat approximately $\mathbf{5 0}$ days old; for Groups E2 and C2 the chamber was empty. Frequency of lever pressing, in all conditions, was recorded on print-out counters, set at a 30 sec rate. 


\section{Results and Discussion}

Due to the matching procedure there was no difference in the response rate of the four groups during the baseline period. Groups E1 and E2 showed an increase in responding on the first session in which light was available compared with the last day of the baseline period (Sign test: $E 1-x=0, p=0.002$; $E 2-x=1, p=0.02$ ), while Group $C 2$, for which conditions remained the same throughout the experiment, showed no such increase over these two days (Sign test: $x=5, p=0.746)$. The average response rate per rat during the sessions when light was available was significantly greater for Group E1 than for Group E2 (Mann-Whitney $U$ test, one-tailed: $U=20, p<.05$ ). That is, animals responded more if the illuminated display chamber contained a young live rat than if it was empty. Thus far, the analysis of the results is in accordance with the findings of Butler (1954), who showed that monkeys would respond more to view a room containing a monkey than to view an empty room. However, Group $\mathrm{C} 1$, which had a rat in the display chamber, but no response-contingent illumination, also showed an increase in responding on the first experimental session as compared with the last baseline session (Sign test: $x=1, p=0.02$ ). Thus there would appear to be some response facilitation effect associated with the presence of a rat in the display chamber. The experimental design used enables an assessment of the different stimulus factors operating in this situation.

The average response rate for each rat was taken for the baseline period (B) and for the experimental period (X). A difference value $D(=X-B)$ was calculated for each rat. These individual $D$ values were then summed and averaged for each group, to give a $D$ value of 13.2 for $\mathrm{C} 1,6.37$ for $\mathrm{C} 2,19.87$ for E1 and 12.7 for E2. Since $\mathrm{C} 2$ is equivalent to a baseline or operant condition, we may use the $\mathrm{D}$ value of this group to assess the additional effects due to other stimulus factors. Thus, if we take $\mathrm{Cl}-\mathrm{C} 2$, this will indicate the increase in responding due to the presence of a rat in the display chamber: 13.2 $6.37=6.83$. Similarly, E2 - C2 gives a value for the light only effect: $12.7-6.37=6.33$. To check this analysis, one may predict now that under condition E1 (light+rat), the two separate effects, if they are proportioned as we hypothesize, should summate to produce an overall greater effect. This, of course, is additional to the basic control or operant response rate (C2):

$$
\begin{aligned}
\mathrm{E} 1 & =\mathrm{C} 2+(\mathrm{C} 1-\mathrm{C} 2)+(\mathrm{E} 1-\mathrm{C} 2) \\
& =6.37+6.83+6.33 \\
& =19.53 \text { (predicted). }
\end{aligned}
$$

The observed $D$ value for $E 1$ is actually 19.87 , which fits the prediction very closely, thus allowing fairly precise assessment of each of the stimulus factors.

Thus it seems that what appeared to be a greater reinforcing effect produced by light + rat as opposed to the light alone was an artifact due to a response facilitation factor, and that a simple light reinforcement effect only was being demonstrated in Groups E1 and E2. The use of a light reinforcement procedure to allow an animal visual exploration of a stimulus enables an assessment of response facilitation which is perhaps not possible in the conventional window opening procedure.

\section{References}

BARNES, G. W., \& BARON, A. Stimulus complexity and sensory reinforcement. J. comp. physiol. Psychol, 1961, 54, 466-469.

BARNES, G. W., KISH, G. B., \& WOOD, W. O. The effect of light intensity when onset or termination of illumination is used as reinforcing stimulus. Psychol. Rec., 1959, 9, 53-60.

BUTLER, R. A. Discrimination learning by rhesus monkeys to visualexploration motivation. J. comp. physiol. Psychol, 1953, 46, 95-98.

BUTLER, R. A. Incentive conditions which influence visual exploration. J. exp. Psychol., 1954, 48, 19-23.

DEMBER, W. N., EARL, R. W., \& PARADISE, N. Response by the rat to differential stimulus complexity. J. comp. physiol. Psychol, $1957,50,514518$.

STEVENSON, M., \& SIMMEL, E. Adult social exploration in the rat as a function of pre- and postweaning social experience. Psychon. Sci, 1967, 7, 253-254.

WILLIAMS, D. I., \& LOWE, G. Bar pressing in the rat as a function of variable visual stimulation. Psychon. Sci., 1967, 7, 231-232. 